\title{
Diffusion of the Internet and low inflation in the information economy
}

\author{
Huub Meijers * \\ Maastricht Economic Research Institute on Innovation and Technology MERIT, University \\ Maastricht, P.O. Box 616, 6200 MD Maastricht, The Netherlands
}

Received 1 September 2004; received in revised form 2 February 2005; accepted 2 February 2005

Available online 3 March 2005

\begin{abstract}
The adherents of the so-called 'New Economy' claim that we are entering a new era with high output growth, low unemployment and low inflation. ICT investments in general and the increased use of the Internet play an important role in this claim. In the literature we find three different explanations for the low inflation experience. Increased productivity growth combined with sluggish adjustment of wages, improved credibility of monetary policy and improved functioning of the labour market. This paper provides another explanation where adoption of Internet as a cost reducing and efficiency improving technology changes market structures and affects the mark-up margins of firms and thereby the relation between costs and output prices. The diffusion of the Internet as a cost saving technology is introduced in a model with network effects and dynamic market structures. The latter two result in an endogenous diffusion process of the use of the Internet for business-to-business commerce. However, there is also some feedback from the increased adoption of the Internet. Diffusion also affects the market structure and therefore the gains of the efficiency improvements obtained by doing business via the Internet. The combination of the diffusion of the Internet, the characteristics of network effects and the dynamics of the markets can explain variation in the mark-up on production costs explains at least a part of the low inflation experience. However, the model also predicts that the inflation suppressing effect of the increased use of the Internet eventually will cease and that inflation will increase in the longer run. The paper adds two new elements to the existing literature. First, it describes a model that combines network
\end{abstract}

\footnotetext{
* Fax: +31433884905 .

E-mail address: huub.meijers@merit.unimaas.nl.
} 
effects with changes in market structures to explain the diffusion of a cost reducing technology, i.e. the Internet. Second, it uses this model to explain the current low-inflation experience.

(c) 2005 Elsevier B.V. All rights reserved.

JEL classification: D43; E31; O33; O38

Keywords: New Economy; Internet diffusion; Inflation; Cournot Oligopoly model

\section{The Information economy, productivity and low inflation}

It is a well-established view that investments in information and communication technologies (ICTs) have a positive impact on productivity. Whereas this relation has been absent for many years, leading to a vast literature on the so-called Solow paradox, the developments in the last decade, especially in the US, led many authors to conclude that ICT investment indeed pay off. ${ }^{1}$ There is even some evidence that investments in ICTs lead to positive network externalities such that productivity gains are larger than anticipated by investors and are larger for larger networks in which firms operate. ${ }^{2}$ Apart from boosting productivity, the 'Information Economy', or 'new economy', shows a remarkable relation between inflation and unemployment. There is ample evidence that the non-accelerating-inflation rate of unemployment (NAIRU) has been fallen in the last decade. Several reasons are addressed in the literature. Ball and Moffitt (2001a,b), Ball and Mankiw (2002), among others, show evidence that wage rates adopt slowly to changes in productivity such that a boost in productivity is not immediately followed by an increase in wage rates such that total wage costs fall. ${ }^{3}$ This effect explains both the rise in the NAIRU in the 1970 s, a period characterized by the productivity slowdown where growth in wage rates did not adopt to the fall in productivity growth as a result of which the NAIRU rose, as well as the more recent opposite developments.

Another explanation for the falling NAIRU is the increased transparency of the labour market and reduced search and matching costs due to online matching agencies. If indeed the labour market has become more efficient, the Beveridge curve which shows the relation between unemployment and vacancies - shifts inwards such that upward pressures on the wage rate starts at a lower level of unemployment. (See e.g. Ziesemer (2003) and Ihrig and Marquez (2004)). Although this could explain the

\footnotetext{
${ }^{1}$ For a discussion on the Solow paradox and possible explanations, see e.g. Berndt and Malone (1995), Diewert and Fox (1999), Triplett (1999), Gordon (2000), Moulton (2000). For more recent evidence on ICT investment and productivity growth, see e.g. Jalava and Pohjola (2002), Jorgenson (2001), Pilat et al. (2002), van Ark (2002), Daveri (2002), van Ark et al. (2003).

2 See e.g. Becchetti et al. (2003) and Meijers (2004). Stiroh (2002) does not find any network effects on a sectoral level for the US. However, he does not include lagged effects of ICT investments which are typically found by other authors.

${ }^{3}$ Kiley (2003) argues that productivity should enter the Phillips curve as a proxy for inflation expectations such that the NAIRU should fall when productivity growth increases.
} 
decline of the NAIRU in the last decade, it is less clear that matching on the labour market matching deteriorated in the 1970s.

In this article we provide for another explanation. The introduction of ICTs as efficiency increasing technologies in the production of goods and services also affects market structures and firms will adjust their mark-up margins on marginal costs. This implies that a decrease of the mark-up margin leads to lower prices even if wage rates are instantaneously adjusted to changes in productivity. In their econometric study Brayton et al. (1999) show that indeed the changing mark-up margin explains the falling NAIRU. Here we provide a theoretical underpinning of this finding. The adoption of Information and Communication Technologies has an impact on price developments in two ways. First, as elaborated by Ball and Moffitt (2001a,b) and Ball and Mankiw (2002), it increases productivity and due to sluggish adjustment of the wage rate to changes in the rate of labour productivity growth, total wage cost decrease leading to lower prices. A second, additional effect is elaborated in this paper and materializes through changes in the mark-up margin. If the mark-up margin decreases, for instance through increased competition, output prices will reduce even if the wage rate is in line with productivity growth. Both effects work in the same direction and thus amplify each other. Note also that wage rates will eventually adopt to productivity growth rates and changes in mark-up margins will cease so that both effects are temporary.

The remainder of this article is organized as follows: next section describes briefly the literature on the NAIRU and focuses on the recent developments concerning productivity and the shifting Phillips curve. After that we describe our model in a non-formal way as to present the general ideas of the model and its relation to the decline (and increase) of the NAIRU. A formal version of the model is presented subsequently and by means of simulations we demonstrate the working of the model. Finally, some conclusions close the article.

\section{Low inflation, productivity growth and a varying mark-up margin}

The US economy shows a continuing GDP growth of more than 3 percentage per year since 1994. In correspondence with the high level of growth, unemployment has been falling from $6 \%$ in 1994 to $4 \%$ in 2000 and has increased again towards about $6 \%$ in $2003 .{ }^{4}$ This low level of unemployment was below its presumed NAIRU (NonAccelerating-Inflation Rate of Unemployment) for more than 6 years. From the theory on the NAIRU, we expect that the rate of inflation should accelerate in these circumstances. However, the rate of inflation did not accelerate and has been more or less steady around $2-2.5 \%$ since 1992 . The NAIRU is closely related to the (expectations augmented) Phillips curve which predicts an upward change of the rate of inflation in times of low unemployment. However, a simple graph depicting the relation between the rate of unemployment and inflation - which underlies the original Phillips curve - shows that this is not the case (see Fig. 1). In this figure, we can distinguish three areas. The early 1970s and most of the 1980s and early 1990s show

\footnotetext{
${ }^{4}$ All data used are obtained from BLS and BEA.
} 


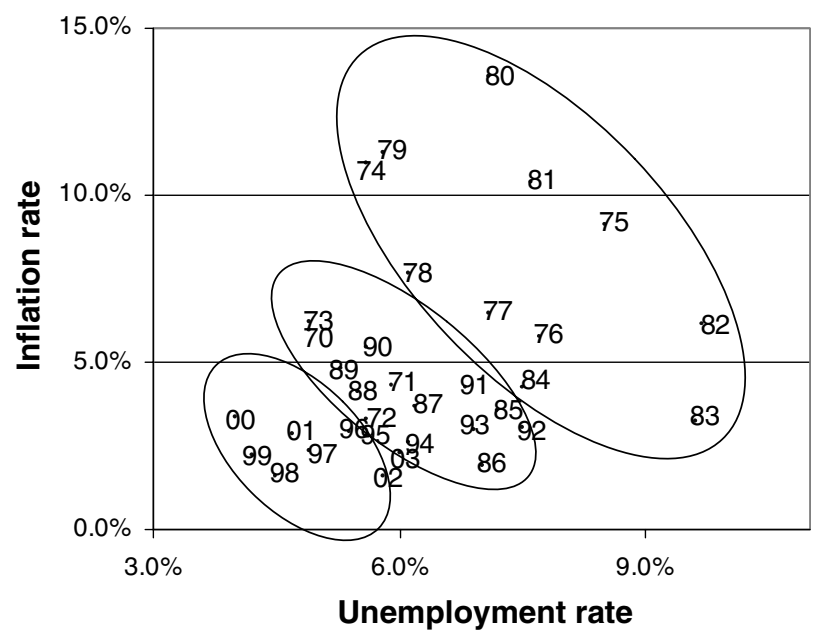

Fig. 1. Inflation and unemployment in the US, 1970-2003.

moderate levels of both unemployment and inflation. Since the mid-1970s, after both oil crises, we see rather high levels of inflation and high levels of unemployment. Since the mid-1990s the US economy experienced low inflation and low levels of unemployment, although the developments in 2003 indicate a return to more moderate levels. So both the theory on the NAIRU and the theory on the (augmented) Phillips curve predict an upward change of the inflation in the present case of (very) low unemployment and high output growth and we cannot discover such upward change by a simple visual inspection of the data, especially in the period 1995-2002. ${ }^{5}$

Fortunately, we have also some empirical evidence that inflation is very low compared to the level of unemployment. Brayton et al. (1999) estimate the NAIRU by means of a standard Phillips curve concept first. The resulting NAIRU is about $6 \%$ using various measures of inflation with a standard error of about 0.2 if they use a short sample from 55Q1-89Q4, so until the start of the 1990s. By extending the sample period to include more recent data (until 98Q4), they obtained about the same estimation results with only a slightly lower NAIRU. However, they extended the estimations by allowing for a single time shift of the intercept and all equations showed a significant shift. The exact date of this shift varies between 1994 and 1995 depending on the measure of inflation employed, but they are all significant. The resulting pre- and post-shift levels of the NAIRU's decrease considerable from around $6 \%$ before the shift to a range of about $4-5 \%$ after the shift, depending on the measure of inflation. ${ }^{6}$

\footnotetext{
${ }^{5}$ The literature on the Phillips curve and related concepts like the wage curve is very rich, theoretically as well as empirically. Discussions on this topic are for instance Akerlof et al. (1996) and Blanchard and Katz (1997) on the NAIRU. Blanchflower and Oswald (1995) give an introduction to the wage curve.

${ }^{6}$ Other estimates of time variation in the NAIRU, including the Kalman filter and cubic spline functions, showed a reduction of the NAIRU in roughly the same period indicating a significant but not sudden decline of the NAIRU in the mid-1990s.
} 
From this we can conclude that the standard estimates of the NAIRU indeed shows a shift in the mid-1990s. Before this time, the NAIRU is about $6 \%$, which is a value also found for earlier periods. After 1995, the NAIRU has been considerable lower. This means that indeed the rate of unemployment can be lower without leading to an upward pressure of inflation in the most recent period. Ball and Mankiw (2002) find similar movement of the NAIRU using a Hodrick-Prescott filter to distinguish short-term movements from longer-term trends. In line with the developments depicted in Fig. 1 the NAIRU indeed increases in the 1960s and 1970 s from $5.4 \%$ in 1960 to $6.8 \%$ in 1979 and falls afterwards to $4.9 \%$ in 2000. Similar figures are found by Staiger et al. (2001).

In search for explanations for this reduction, Ball and Mankiw (2002), Ball and Moffitt (2001a,b) and Ihrig and Marquez (2004) give three possible explanations: (a) increased productivity growth, (b) structural changes in the labour market and (c) improved credibility of monetary policy. If increases in (labour) productivity growth are not absorbed by the wage rate, due to sluggish adjustments of the latter, total labour costs will fall, ceteris paribus, leading to reduced increases of output prices, i.e. to lower rates of inflation. Ball and Mankiw (2002) and Ball and Moffitt $(2001 a, b)$ show that this effect can explain most of the developments in the US. Ihrig and Marquez (2004), however, point out that this is not the case for other OECD countries. Instead, they argue that structural changes in the labour market are the driving force of low inflation in most OECD countries. Ziesemer (2003) points into the same direction and argues that the use of ICT and the Internet in particular has improved matching on the labour market. Finally, Ihrig and Marquez (2004) find that monetary policy has become more credible in the late 1990s but they could not find a relation between policy credibility and reductions in inflation. Brayton et al. (1999) point to another possible explanation and argue that changes in market structures and the mark-up on prices in particular, can break down the relation between wage costs and output prices. Changes in the mark-up on unit labour cost cause a gap between the movement of the wage costs and inflation, even if changes in labour productivity would be fully and instantaneously absorbed by wage rates. Indeed, the mark-up increased in the beginning of the 1990s from about its average value to $3 \%$ above its average value in 1995-1996. Since then, it has been falling such that the lower inflation in the most recent years can be explained. Also a formal estimation including the lag of the mark-up over unit labour cost shows a significant influence of this variable and does not show a structural shift within the entire sample period. Brayton et al. (1999) do not give a theoretical explanation of a decreasing mark-up margin, however.

The question arises whether the increasing importance of the Information Economy and the use of the Internet can explain such shifts in the mark-up. In the next sections we will develop a model that explains both the diffusion of the Internet as well as changes in the mark-up margin on marginal cost. The possibility of a variable mark-up, however, requires an imperfect competitive market. The basic idea is that if some firms use the Internet in their business-to-business contacts, they are able to decrease the marginal production 
costs. ${ }^{7}$ This implies that their market power increases such that the mark-up margin can be increased. As more firms invest in the Internet, competition in the 'low marginal cost market' increases and the market power of these firms start to decrease. The Cournot oligopoly model appears to be a simple model that can explain such behaviour. ${ }^{8}$ In this paper we want to explain two observations: (i) endogenous forces that take care of the diffusion of the Internet and (ii) changes in the mark-up margin as to explain the low-inflation experience in combination with low unemployment. Using a model that is as simple as possible seems to be a good starting point and does not divert our attention from these main issues to be addressed. The extension of the simple Cournot model towards a more sophisticated model that overcomes this limitation is left for further research. ${ }^{9}$

\section{The Model: a non-formal description}

Below we present a diffusion model that explains the dynamics of the mark-up from the adoption of the Internet. By doing so, it creates a theoretical link between the use of the Internet and the low-inflation experience. In a nutshell, the model runs as follows. Firms producing final output are assumed to operate in a number of independent sub-markets. The focus of this paper is on one specific sub-market in which $n$ firms are active. In the initial situation, all transactions between these firms and the intermediate goods producing sectors run through traditional channels, i.e. ordering goods, billing, exchange of information etc. is done in a traditional manner. The transaction costs are high and the intermediate goods producing sector is not very transparent such that the intermediates can exploit some monopoly power. In the final output producing sector, the sub-markets are assumed to be monopolistic competitive with a constant mark-up margin on unit production costs.

In the first phase of the diffusion of the Internet, the early adopters in the final output market experience some efficiency gains by using the Internet. The transaction costs of the deliveries between intermediate producing firms and the final output-producing firms decrease. Both firms can appropriate a part of these efficiency gains and because other firms still face higher transaction costs, the efficiency gains lead to an increase of gross profits. But because there are just a few, or no, other firms who use the Internet, the efficiency gains in terms of lower marginal production costs are rather small.

However, the presence of network effects is one of the main characteristics of networks like the Internet. If more firms invest in the Internet, more suppliers of

\footnotetext{
${ }^{7}$ It is well known by now that the size of business-to-business commerce outweighs business-toconsumer commerce (see e.g. European Information Technology Observatory, 2000). Therefore we concentrate on the first type of e-commerce.

8 An article of Yi (1999) inspired the use of the Cournot model in this paper.

${ }^{9}$ Candidates are for instance the Bertrand model with capacity constraints and decreasing returns to scale, or (infinitely) repeated game models.
} 
intermediate goods will also do so and more applications will become available such that the marginal production costs will decrease if more firms use the Internet for their business-to-business commerce. This creates new incentives for other firms to invest in Internet technologies and the efficiency gains increase for all users. In the mean time, the relative number of firms is still small and the profits of these early adopters are relative high. This creates incentives for other firms to invest in Internet technologies too. Again, this causes an increase of the efficiency gains, but it also implies that more firms can produce against the same, low, marginal cost such that the markets become more competitive. The profits of the Internet using firms decrease but are still higher than the profits of the laggards. More important, due to the increased competition on the 'low marginal cost market', the mark-up margin on production cost decrease, which is exactly what we want to show. So we use the diffusion of the Internet as an explanation of the mark-up margin on marginal cost in the first phase and a decrease of the mark-up in the second phase of the diffusion process. This fits exactly in the econometric explanation given by Brayton et al. (1999).

\section{Adopting the Internet}

Firms adopting the Internet for Business-to-Business electronic commerce and for electronic transfer of information report considerable gains in efficiency. ${ }^{10}$ This implies that firms who use the Internet to exchange information; to link their internal information systems with the systems of the suppliers of intermediate goods and services, and for other forms of business-to-business commerce can operate at lower (marginal) cost than firms who do not invest in Internet technologies. It is obvious that not all firms used the Internet for their (business-to-business) commerce from the outset and even if firms moved to the Internet, they did not all do it to the full extent immediately. Studies on adoption and diffusion of new technologies focus on such transition processes and try to explain why not all firms move immediate to a new (more profitable) technology.

Although there are many different explanations mentioned in the literature most of them can be explained by Fig. 2. ${ }^{11}$ The basic assumption is that firms differ from each other with respect to one or more characteristics that are important for investment decisions. ${ }^{12}$ For instance, some firms can be more risk averse than others, whereas the adoption of a new technology is experienced as an

\footnotetext{
${ }^{10}$ See for instance EITO (2000), Stein and Sweat (1998) and US Department of Commerce (1998). For an overview, see e.g. Bertschek (2003).

11 The literature on adoption and diffusion can be divided in epidemic diffusion models, rational adoption models and strategic adoption models, see e.g. Thirtle and Ruttan (1987) and Reinganum (1989).

${ }^{12}$ An exception is the game theoretic explanations where changing market structures take care of a changing environment such that identical firms in the absence of risk and uncertainty make different choices, see e.g. Reinganum (1989).
} 


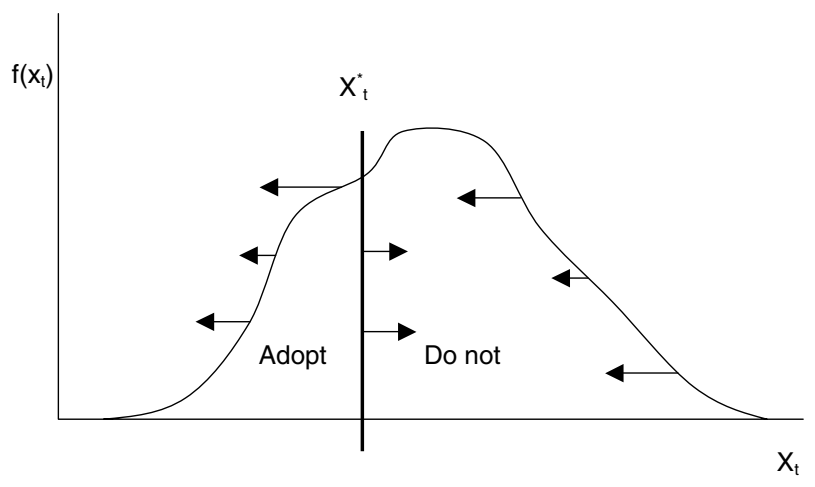

Fig. 2. Adoption of a new technology.

investment that bears some risks, or of which the expected profitability is not known. Other reasons for not adopting technology can be the size of adjustment cost. If investment in a new technology involves cost of adjustment that depends for instance on firm size, small firms, with low adjustment cost, may adopt a new, but costly, technology whereas larger firms, with relative higher adjustment cost, may rationally decide not to adopt. For example, the adjustment costs are plotted along the horizontal axis in Fig. 2 and the number of corresponding firms along the vertical axis. Moving from the left to the right we find firms with increasing (expected) adjustment cost. The net profits - defined as the increased profits minus the investment cost, so excluding adjustment costs - function as a threshold. Firms with expected adjustment cost below the net profits will invest in that technology and other firms not. A diffusion process can be explained if either the threshold moves to the right, e.g. due to decreased investment cost or increased profits, or the distribution moves to the left, e.g. due to decreasing adjustment costs. So a typical characteristic of these probit models is that either moving the threshold or the distribution, or both generate a diffusion curve. The forces behind these movements are either exogenous or endogenous.

For the model developed in this paper we assume that firms are not the same regarding their view on adjustment cost of adopting the Internet as a core instrument for doing business. Investing in the Internet involves adjustment cost because the entire internal (administrative) structure of firms has to be adjusted for a successful transformation towards Internet based commerce. This implies that for instance larger firms may experience relative larger adjustment cost than smaller firms do. Of course, there can be other differences such as the initial level of computerisation that can influence the adjustment costs considerable (e.g. SME's with no ICT-experience vs. larger high-tech firms).

As introduced above, we assume that firms operate in sub-markets with a homogeneous product and initially with the same marginal cost $\left(c_{0}\right)$ and the same profits $\left(\pi_{0}\right)$. After adopting the Internet, the marginal production cost decreases to $c_{1}<c_{0}$ and the profits will increase to $\left(\pi_{1}>\pi_{0}\right)$. If firms expect profits to remain constant after the adoption, they will invest in the Internet if total investment cost $(I)$, includ- 
ing the cost of adjustment, are at the most equal to the difference of the discounted profit streams to be earned in the future. ${ }^{13}$ Let $V_{0}$ be the expected discounted profit stream of production without using the Internet and let $V_{1}$ be the profit stream if a firm moves to the Internet at some time $t_{1} . V_{0}$ and $V_{1}$ are defined as

$$
V_{0}=\int_{0}^{\infty} \pi_{0} \mathrm{e}^{-r t} \mathrm{~d} t \text { and } V_{1}=\int_{0}^{t_{1}} \pi_{0} \mathrm{e}^{-r t} \mathrm{~d} t+\int_{t_{1}}^{\infty} \pi_{1} \mathrm{e}^{-r t} \mathrm{~d} t-I \mathrm{e}^{-r t_{1}},
$$

where $r$ denotes the discount rate. So a firm will invest in the Internet if $V_{1}>V_{0}$. First assume that the firm decides to invest in the Internet. The entrepreneur has to determine the moment of investment $t_{1}$. However, because we assume that firms expect profits, investment costs, and the discount rate to be constant, it is easy to see that the optimal moment of investment is either now $\left(t_{1}=0\right)$ or never $\left(t_{1}=\infty\right) .{ }^{14}$ So if the discounted difference in profits exceeds the investment cost, firms will switch immediate, otherwise they will switch never, conditional on constant (expected) profits and constant (expected) investment cost. So what remains is the question whether a firm will invest in the Internet or not. A firm will invest in the Internet if $V_{1}-V_{0}>0$. That is, if

$$
I \leqslant \int_{0}^{\infty}\left(\pi_{1}-\pi_{0}\right) \mathrm{e}^{-r t} \mathrm{~d} t=\left(\pi_{1}-\pi_{0}\right) \int_{0}^{\infty} \mathrm{e}^{-r t} \mathrm{~d} t=\frac{1}{r}\left(\pi_{1}-\pi_{0}\right) .
$$

If we redefine the investment cost as to include the discount rate, we can just compare these cost, denoted by $I^{\mathrm{UCC}}$, with the difference in current (expected) profits. As we disregard depreciation as well as future changes in prices of Internet investments, this term is equal to the user costs of capital. So firms will invest in the Internet for their business-to-business commerce if the user cost of capital of Internet investments is smaller than the expected gains:

$$
I^{\mathrm{UCC}} \equiv I \cdot r \leqslant\left(\pi_{1}-\pi_{0}\right) .
$$

If the expected difference in profits exceeds the user costs of capital firms will invest in Internet technologies and adjust their business to be able to gain from doing so. Otherwise they rationally decide not to invest in Internet technologies. As we have discussed above, firms differ from each other with respect to the adjustment cost, which implies that $I^{\mathrm{UCC}}$ is firm specific. Firms with a low $I^{\mathrm{UCC}}$ will invest in the Internet sooner then firms with a larger $I^{\mathrm{UCC}}$.

\section{A simple oligopoly model}

Now we will move to a simple oligopoly model with two technologies. As introduced above, both are characterised by constant marginal cost, $c_{0}$ and $c_{1}$. In order to

\footnotetext{
${ }^{13}$ Note that we treat expectations entirely adaptive. An alternative would be to apply a Markov Perfect Equilibrium (see e.g. Maskin and Tirole (1987), albeit in a duopoly setting), but this goes beyond the scope of this paper.

14 As no uncertainty plays a role in our model, we exclude the option theory version of technology adoption in which waiting - and in the mean time learning — can be advantageous. See e.g. Stoneman (2002) for on overview of this theory.
} 
be able to solve the model analytically, we assume a linear demand function: $P=a-Q$, where $P$ is the price of the final goods which is the same for all firms in the Cournot model, $Q$ is the total amount of goods and $a>c_{0}$ is a constant. ${ }^{15}$ Let the number of firms that use the Internet (the "users") be $m$ and let the total number of firms be $n$, so there are $(n-m)$ firms who do not use the Internet, the "non-users". The total output is given by $Q=m * q_{1}+(n-m) * q_{0}$, where $q_{1}$ and $q_{0}$ are the output of firms with and without using the Internet, respectively. Let the marginal cost of the non-users be $c_{0}$ and the marginal cost of the users be $c_{1}$ where $c_{0}>c_{1}$.

The profits of non-users and users are defined as $\pi_{i}=q_{i} *\left(P-c_{i}\right)$ for $i=0,1$. Solving the Cournot model by maximising profits by selling the appropriate quantity yields

$$
\begin{aligned}
& q_{0}=\frac{a-c_{0} *(m+1)+c_{1} * m}{1+n} \text { and } \\
& q_{1}=\frac{a+c_{0} *(n-m)-c_{1} *(n-m+1)}{1+n} .
\end{aligned}
$$

So lowering the marginal cost of technology $i$ will increase the quantity produced by firms using this technology and decrease the quantity produced by the other firms, $j \neq i$. This holds true for both the users and the non-users. This means that firms with lower marginal cost will serve a larger share of the total market, i.e. they have more market power. The output price in the optimum is equal to $P=\left(a+c_{0}(n-m)+c_{1} m\right) /$ $(1+n)$ such that the profits generated by these firms is given by

$$
\begin{aligned}
& \pi_{0}(m)=\frac{\left(a-c_{0} *(m+1)+c_{1} * m\right)^{2}}{(1+n)^{2}} \text { and } \\
& \pi_{1}(m)=\frac{\left(a+c_{0} *(n-m)-c_{1} *(n-m+1)\right)^{2}}{(1+n)^{2}}
\end{aligned}
$$

which is simply the square of the output. As is to be expected, a decrease of the marginal cost of the users will increase the profits of these firms, but will also decrease the profits of the non-users. So firms with lower marginal cost will also have higher profits.

Let us now analyse the effect of an increase of the number of users, i.e. an increase of the number of firms that uses the Internet. Differentiating the profit functions with respect to the number of Internet users shows that the profits of both the Internet users and the non-Internet users decline if the number of Internet users increases. So the competitive pressure on the 'low marginal cost market' increases if a non-user becomes a user as a result of which the profits of all other users decrease. Moreover, due to the very same pressure, the profits of the non-users also decrease. So if a firm invest in the Internet and becomes a user, both the profits of the other users, as well as the profits of the remaining non-users will decline. Of course, the (gross) profits of

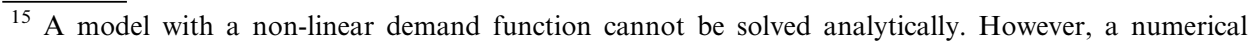
solution is presented below.
} 
the innovating firm increases. As we have seen above, the difference between profits relative to the adjustment costs are relevant for the investment decisions of firms (cf. Eq. (3)). Moreover, it is the evolution of this difference that eventually determines the diffusion process. Taking the derivative of the difference in profits with respect to the number of Internet users, it is easy to show that this results in

$$
\frac{\mathrm{d}\left(\pi_{1}-\pi_{0}\right)}{\mathrm{d} m}=-\frac{\left(c_{0}-c_{1}\right)^{2}}{1+n}
$$

which is independent of the number of Internet users. So although both the profits of the users and the non-users decrease as the number of users increase, the difference in profits between users and non-users remains exactly the same. This means that if one firm becomes a user because it expects that the investment cost of becoming a user are smaller than the gains, there is no additional incentive for other firms to become a user too. Or, talking in terms of the model presented in Fig. 2, neither the threshold nor the distribution move, so a fraction of all firms will adopt the Internet immediately and others will never do. This is not what we experience in real life.

\section{Introducing network effects: from EDI to e-business}

Above we assume constant marginal production costs for both the users and the non-users of Internet technologies. It is questionable whether this is a realistic assumption. Taking a closer look to the way firms use the Internet for their business-to-business commerce, we expect that in the first phase of business-to-business Internet commerce, only a few firms used this technology and that the gains were not that significant. For instance because firms had to use dual communication systems, in the broadest sense of the word, for the simple reason that some of their relations used the Internet and others not. Moreover, in the early days there was no or ill integration of Internet enabled software with for instance ERP systems. If more firms move to the Internet, the efficiency gains will increase due to network effects. ${ }^{16}$

In this respect, a comparison with Internet technologies and the longer existing concepts of Electronic Data Interchange (EDI) is useful. EDI is based on standards concerning the exchange of data in the sense that the format of the business documents to be exchanged is standardized. Although the idea of standardisation of these messages is useful, the EDI concept has some drawbacks. One is the enormous amount of different standards. Almost each industry has its own standards so doing business with many different industries, for instance for the purchase of intermediate goods, a firm has to implement all these different standards. ${ }^{17}$ The second drawback

\footnotetext{
$\overline{16}$ For a brief description and overview of new technology adoption, see e.g. Hall and Khan (2003) and Stoneman (2002).

${ }^{17}$ There are some efforts done - especially by the UN - to come to an international standard across all sectors of industry called EDIFACT (EDI for Administration, Commerce \& Transport) but not all companies have embraced it.
} 
is that the EDI concept is only limited to the format of the documents to be exchanged, i.e. it is limited to the format of the messages. The way firms exchange information, that is, the formats firms use to exchange the messages is not standardized in the EDI concept. This is exactly the point where the Internet comes in the picture. On the Internet, the messages as such are not standardized but the way information is transferred is laid down in open protocols. Moreover, the entire process is divided into several layers and each layer has its own protocols. For instance, the top layer of the Internet protocol is the application layer and this layer gives the specifications for the applications using the network such as how to send a request, how to respond to a request, how to specify a filename etc. The next layer is the presentation layer which defines how data are represented, so how a number is represented, how a character and so on. This goes down to the last, seventh, layer which is the physical layer. This layer takes care of the basic hardware components for networks such as the voltage used, how individual bits are represented and so on. This model has several advantages. The most important advantage is that all standards are open and are publicly available. This implies that competitive firms can develop devices and software which are compatible to the rest of the network. This has led to numerous applications and tools that are all compatible to the Internet standards. These applications and tools are by now widely available at low costs and they are often integrated in operating systems and other applications. So the main difference between EDI and the Internet is that EDI specifies the format of the messages whereas the Internet specifies the way information, i.e. these messages, is transferred. Currently both protocols will be integrated through a new Internet standard XML that allows for standardised messaging via the Internet.

What does this mean for the marginal production costs? The EDI concept without using the Internet requires huge investment costs since the actual transportation of messages was not standardized. This implies that only the bigger firms were able to implement EDI. Moreover, because of the non-standardized way of message transports the gains through network effects were absent or limited in size. If more firms move to the Internet however, the efficiency gains are higher due to a more efficient and integrated approach, due to increased competition on the market for intermediate goods and due to cheaper and better (integrated) software packages. This means that the efficiency gains of using the Internet will increase if more firms move to the Internet. That is, the efficiency gains of using the Internet for business-to-business commerce can be characterised by network effects, i.e. it becomes more efficient for every user if more firms move to the Internet. Although we do not specify the exact underlying process, we assume that the efficiency gains are an increasing function of the number of Internet users. This means that the marginal cost of the users decrease with the number of users. Next to this, it is only natural to expect that there is some upper limit of these efficiency gains. We assume that the second derivative of the marginal cost with respect to the number of users is positive and becomes zero such that the marginal costs reach some lower limit asymptotically. Hence, the decrease of marginal cost is rather large in the beginning of the diffusion process but becomes smaller and smaller as the number of users increases. To be more precise, we assume that 


$$
c_{1}(m)=\frac{c_{1,0}}{\beta+(1-\beta) \cdot \alpha^{m}} \quad 0 \leqslant \alpha \leqslant 1, \quad \beta>1, c_{1}^{\prime}<0, c_{1}^{\prime \prime}>0,
$$

where $\alpha$ controls the speed at which the marginal cost decline and $\beta$ determines the level of the asymptote. If the number of users is zero, the marginal costs are equal to $c_{1,0}$ whereas for a large (or infinite) number of users the marginal cost become $c_{1,0} / \beta$.

A crucial aspect at this point is the treatment of expectations of firms regarding the network effects. As will become clear below, the model becomes very complicated if firms take the adoption decisions of other firms and the future gains due to network effects into account when making their own investment decision. ${ }^{18}$ Moreover, these effects depend on the distribution of firms with respect of the adjustment cost, and in order to be able to take these effects into account, all firms should have knowledge about the adjustment cost of all other firms. This seems to be a very strong assumption. Therefore we assume that firms have knowledge about the marginal cost, given the number of users in the previous period, that is, we assume that the firms get informed about actual value of the marginal cost but they do not take future gains into account and expect profits to remain constant. So we assume that the expected marginal cost of a user in period $t$ is equal to $c_{1}\left(m_{t-1}\right)$. The (expected) marginal cost of the non-users remains the same as before at $c_{0}$.

Solving the model in the same way as we have done above, the profits of the nonusers and the users are given in Eq. (5), except that the constant marginal cost of the users $\left(c_{1}\right)$ now is replaced by the function $c_{1}\left(m_{t-1}\right)$. Recall that the difference of profits between users and non-users was independent of the number of users in the analysis above. Due to network effects this is not true any more. To see this, investigate a change in profits of non-users and of users due to a change of the number of users $(m)$ in Eq. (5) where now $c_{1}$ is a function of $m$. Differentiation of the difference in profits with respect to the number of users as we have done above in Eq. (6) does not lead to a better understanding so we will use a less formal first difference approach. If we disregard the denominator, which is the same in both profit functions, and if we disregard the square in the nominator, an increase of $m$ by one changes the profits of the non-users by $-c_{0}+c_{1}+m \Delta c_{1}$ whereas the profits of the users changes by: $-c_{0}+c_{1}+-(n+1-m) \Delta c_{1}$. It is obvious that $\Delta c_{1}$ is zero if there are no network effects and that the difference in profits does not depend on the number of users, as we have seen before. However, with the introduction of network effects, this does not hold any more. In the beginning of the diffusion process, when $m$ is small relative to the number of firms, the decrease in profits of the non-users due to the network effects is rather small. However, these effects are rather large for the users. This implies that the network effects are more important for the users than for the non-users as a result of which the difference in profits increases in the beginning of the diffusion process. This effect is augmented by the assumption that the network effects are relative strong in the beginning of the diffusion process. If the number of users becomes larger and larger, things turn around and the network effects become more important

\footnotetext{
${ }^{18}$ For a two period adoption model with perfect foresight, see for instance Katz and Shapiro (1986). Two periods would be far to less to make our point in this paper and is ruled out.
} 
for the non-users than for the users. The difference in profits between users and nonusers ceases and even will decrease at the end of the diffusion process. This process is not symmetric because the network effects become smaller for large values of $m$, relative to the total number of firms $n$.

The above implies that firms with low adjustment cost will invest in Internet technologies rather early. This creates network effects such that the difference in profits increases. This creates incentives for other firms with larger adjustment costs to invest in the Internet too. This process repeats until the number of users becomes large and the network effects tend to cease. It is possible that there will remain some firms for which it is not profitable at all to invest in the Internet such that they will remain non-users forever. The output price in the optimum is the same as above with $c_{1}$ being replaced by $c_{1}(m)$ such that $P=\left(a+(n-m) \cdot c_{0}+m \cdot c_{1}(m)\right) /(1+n)$. The first derivative of the price level with respect to the number of users $(m)$ is always negative, as expected. As is in the case without variable marginal cost the output price decreases as the number of users of Internet technology increases. Without network effects, there are no additional incentives for firms to invest in the Internet if the initial difference of (discounted) profits do not recover the investment costs. However, because of the introduction of network effects, the adoption of Internet technologies for e-business purposes is endogenously driven. This implies that the diffusion of the Internet as a cost reducing technology decreases prices, ceteris paribus, and that the level of inflation is reduced during this diffusion process.

The industry mark-up on marginal cost is obviously a weighted average of the mark-up of the users and the non-users. The weights depend on the number of users and non-users and on the output produced by these firms, and thus depend on the actual distribution of the adjustment costs. So the industry mark-up can only be given for a particular example. This will be done below, but first we will derive the mark-up of the individual users and non-users. The mark-up for both the non-users and the users is defined by markup $_{i}=P / c_{i}-1$ for $i=0,1$ and it is obvious that the mark-up for the users exceeds the mark-up of the non-users. ${ }^{19}$ The mark-ups are given by

$$
\begin{aligned}
\operatorname{markup}_{0} & =\frac{a+(n-m) \cdot c_{0}+m \cdot c_{1}(m)}{(n+1) \cdot c_{0}}-1 \\
& =\frac{a-(m+1) \cdot c_{0}+m \cdot c_{1}(m)}{(n+1) \cdot c_{0}}
\end{aligned}
$$

and

$$
\operatorname{markup}_{1}=\frac{a+(n-m) \cdot c_{0}-(n+1-m) \cdot c_{1}(m)}{(n+1) \cdot c_{1}(m)}
$$

\footnotetext{
$\overline{19}$ Below we will show that this result depends on the demand function we choose. For a non-linear demand function, the mark-up differs from the one presented here. For instance, a demand function with a constant elasticity of substitution leads to a mark-up that only depends, at least in a one technology market, on the number of firms and not on the marginal production cost.
} 
The mark-up for the non-users decreases if the number of users increases due to two effects. The first is the decrease in market power of the non-users, which can be easily demonstrated by leaving the network effects aside and thus assuming $c_{1}$ being constant. If $m$ increases, the 'weight' of $c_{0}$ decreases and the weight of $c_{1}$ increases as a result of which the mark-up of the non-users decreases. The second effect is caused by the network effects, which take care of an even stronger decrease of the marginal cost of the users and thus for a stronger decrease of the mark-up of non-users.

For the users, the same two effects are at work but things are a bit more complicated. Ruling out network effects, the mark-up of users also decreases with the number of users. This implies that the first adopter faces the highest mark-up and that later adopters create more competition on the 'low marginal cost market' such that the mark-up of all firms decreases. However, the network effects now create ambiguous results. De derivative of the mark-up of the users with respect to the number of users yields

$$
\frac{\mathrm{dmarkup}_{1}}{\mathrm{~d} m}=\frac{\left(c_{1}-c_{0}\right)-\frac{c_{1}^{\prime}}{c_{1}}\left(a+(n-m) \cdot c_{0}\right)}{(n+1) \cdot c_{1}},
$$

where $c_{1}^{\prime}$ denotes the first derivative of the marginal costs towards $m$ and where we left out $c_{1}$ being a function of $m$ to save notation. Both the first term and the second term in the nominator are always negative whereas the denominator is always positive. This implies that the sign of the entire term is not determined at first sight. But in the first stage of the diffusion process, the decrease of marginal cost due to an increase of the number of Internet users is strong (cf. Eq. (7)). Moreover, $m$ is small such that $(n-m) c_{0}$ is large. Taking these arguments together, it is likely that Eq. (9) is positive in the first stage of the diffusion process. This implies that the network effect is stronger than the declining market power effect and that the mark-up of the users increases in the first stage of the diffusion process. However, as the diffusion process continues, the decline of the marginal cost becomes smaller and smaller such that the change of mark-up becomes negative. The network effects cease whereas the decline of the market power in the 'low marginal cost market' continues.

Taking these arguments together, the industry mark-up - the weighted average of both mark-ups - always will increase if more firms will use the Internet, given the linear demand function. But if the network effects are sufficient strong, there may occur some 'overshooting' in the sense that the mark-up increases in the first stage of the diffusion but decreases afterwards and finally ends at a level that is higher than before the introduction of the Internet. Except for the final level of the mark-up, this result fits very well in the explanation of low inflation given by Brayton et al. (1999). We will discuss the final level of the mark-up below but first we will give a numerical example as to demonstrate the model.

\section{An example}

To show the working of the model, we need to specify at least the distribution of firms regarding their (expected) adjustment costs. A bell-shaped function is probably 


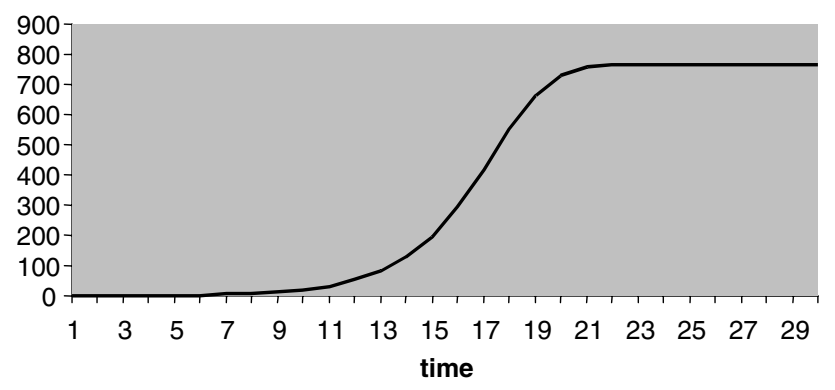

Fig. 3. The number of Internet users.

the best assumption but this would possibly give the impression that if the model results into an S-shaped diffusion curve this would be caused by the Bell-shaped distribution of firms with respect to the adjustment costs. To avoid this false impression we simply assume a uniform distribution. So there are entrepreneurs who judge the investment and adjustment costs as being small as compared to the discounted profits whereas other experience higher total investment costs. ${ }^{20}$ The boundaries of the uniform distribution $\left(\gamma_{\min }\right.$ and $\left.\gamma_{\max }\right)$ are determined such that at least two firms will initially invest in the Internet whereas the upper limit is chosen such that some firms face such high expected adjustment costs that they will never invest in the Internet at all. $^{21}$

As already noted above, we assume that firms are aware of the marginal costs of their competitors such that investment decisions at time $t$ are based on the marginal costs faced by $m_{t-1}$ users. The number of users is then given by $m_{t}=$ $\operatorname{CDF}\left(\pi_{1}\left(m_{t-1}\right)-\pi_{0}\left(m_{t-1}\right) ; \gamma_{\min } \cdot \pi_{\min }, \gamma_{\max } \cdot \pi_{\max }\right)$ where $\operatorname{CDF}(a, b, c)$ is defined as the cumulative distribution function (of the uniform distribution) evaluated at value $a$, for lower and upper boundaries $b$ and $c$, respectively add where we use the integer value of this term in order to solve the indivisibility problem.

Given these parameter settings, the model generates an endogenous S-shaped diffusion pattern as displayed in Fig. 3 where we assume that the Internet becomes available in period 5 . In the first stage, the number of users increases exponentially whereas, due to the combination of decreased market power and ceasing network effects, the number of adopters decreases. The total number of firms in this simulated market is 1000 whereas the upper limit of uniform distribution is arbitrarily set to a value such that about $75 \%$ of the firms will eventually invest in the Internet.

The corresponding profits are given in Fig. 4 and indeed, the profits of non-users decrease as more firms invest in the Internet and are able to produce with lower marginal cost and produce (and sell) more products. The profits of the users even increase in the beginning of the diffusion process. The gains due to the network

\footnotetext{
${ }^{20}$ Recall that it is only the judgment of firms of the investment and adjustment costs that counts in this model. There is no learning and information coming from earlier adopters is ruled out. Of course, such elements could also be used as driving forces for the diffusion process, but they are not needed here.

${ }^{21}$ The procedure applied is described in Appendix A.
} 


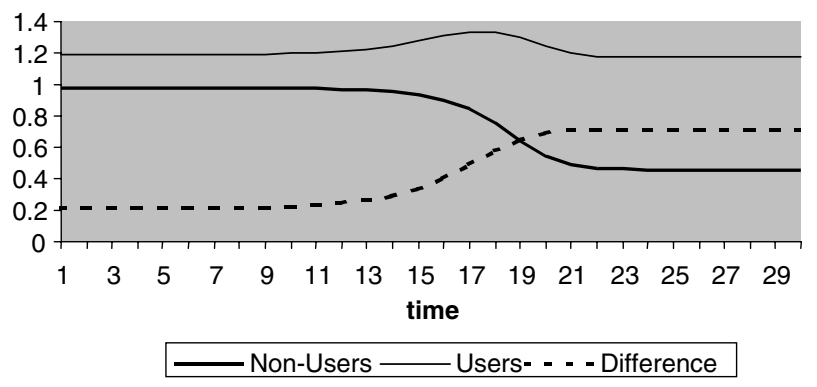

Fig. 4. Profits.

effects exceed the decreasing market power effect. However, as the network effects become smaller and smaller, the decreasing market power becomes more important as a result of which the profits of the users will decline. However, even in that phase of the diffusion process, the decrease of the profits of the non-users exceeds the decrease of the users such that the difference of profits between users and non-users still increases. This implies that still more and more firms will invest in the Internet as is displayed by Fig. 3. Finally, the difference becomes too small to attract another user and the diffusion process stops.

The mark-up on marginal production cost shows a pattern that is similar to the pattern of the profits, as is displayed by Fig. 5. This holds true for both the users and the non-users. However, the mark-up for the entire the industry, which is defined as markup $_{\text {ind }}=\left(\operatorname{markup}_{0} \cdot q_{0} \cdot(n-m)+\operatorname{markup}_{1} \cdot q_{1} \cdot m\right) / Q$, is completely different. Both the number of users and the output produced by these users increases that fast in the first phase of the diffusion process that the industry mark-up first increases. Even at the point where the mark-up of the users already starts to decrease. However, this process is reversed if the number of adopters starts to decrease such that the industry mark-up also decreases. In the end, the industry mark-up reaches a stable level that is slightly higher than before the introduction of the Internet. So the resulting pattern of the industry mark-up fits entirely in the analysis of Brayton et al. (1999) such that the period of low unemployment and low inflation indeed can be explained by the introduction and diffusion of the Internet as a cost reducing technology for business-to-business commerce.

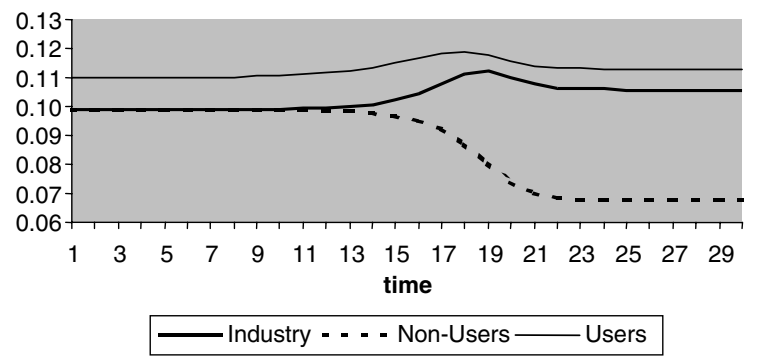

Fig. 5. Mark-ups. 


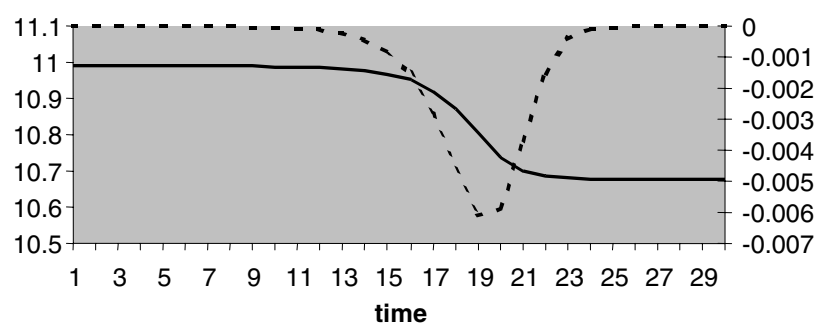

Price level (left scale) - - - - Inflation (right scale)

Fig. 6. Price level and inflation.

The price level indeed decreases during the whole transition period, not only due to the changes of the mark-up, but also due to the use of a cost reducing technology, see Fig. 6. This also means that if prices of input factors such as labour and energy have been increased in the second phase of the diffusion process, the price level could remain at about the same level. This implies that the rate of inflation decreases in the first phase of the diffusion process but it also implies that such a decrease can only be temporary. The rate of inflation starts to rise again as the speed at which industry prices go down decreases and finally it will return to its pre-Internet value if the diffusion process is completed.

\section{Non-linear demand}

In the example presented above, we used a linear (inverse) demand function in order to be able to solve the model analytically. However, for a linear demand function, the mark-up on marginal cost depends on the number of users, also in a one-technology market. For instance, suppose that there is one technology with marginal cost $c$. So we have a standard Cournot model with total demand function $p=a-n * q$. In the optimum, the output for each firms is $q=(a-c) /(n+1)$ and the output price is $p=c+(a-c) /(n+1)$. The resulting mark-up is equal to

$$
\text { markup }=\frac{a / c-1}{n+1}
$$

which indeed says that the mark-up increases as the marginal production cost decrease. In a two technology setting as presented in this paper, this means that if all firms move from one technology to another, the mark-up margin will increase. However, this conclusion depends on the demand function employed. For a more general demand function with a constant demand elasticity, the results are different. For instance, suppose that the demand function is defined as $p=a * Q^{-1 / \varepsilon}$. The price in the optimum is equal to $p=c /(1-1 / n \cdot \varepsilon))$ and the mark-up is then equal to

$$
\text { markup }=\frac{1}{1-\frac{1}{n \cdot \varepsilon}}-1
$$




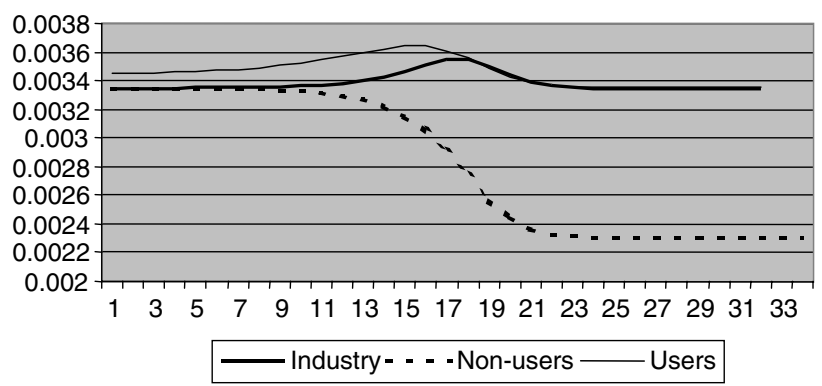

Fig. 7. Mark-ups (non-linear demand).

which is indeed independent of the marginal cost. This means that if we apply a demand function with a constant elasticity of demand to the diffusion model presented above, the final mark-up would be the same as the initial one. Because the mark-up holds true for a one-technology case only, this is only true if all firms adopt the Internet. Otherwise we have to investigate the two-technology market structure which is not solvable analytically for this more general demand function because of the combination of the exponential demand function with the linear production function. (Total output is the number of non-users times the output for each non-user plus the number of users times the output per user.) So it is unclear whether the markup is constant throughout the entire diffusion process. Therefore we used some numerical optimisation methods in order to investigate the movement of the industry mark-up during the diffusion process. ${ }^{22}$ As an example we used the same model where we replace the linear demand function by $p=a * Q^{-1 / \varepsilon}$. For each new value of the number of users, we determine the optimal amount of output for each firm, given the Cournot setting of the model. This leads to new values of profits as is the case in the model with a linear demand function. The results are very similar to the results of the linear demand function and here we only present the mark-up of the users, the non-users and the industry (see Fig. 7). The mark-ups of the users and non-users are quite similar but the industry mark-up is in the end the same as the initial level, so before the introduction of the Internet. ${ }^{23}$ So with the use of a more general demand function we are able to explain the observation that the mark-up margin at the end of the diffusion process is equal to the mark-up margin at the beginning.

\section{Concluding summary and suggestions for further research}

To summarise, this paper presents the diffusion of the Internet as an endogenous process where network effects and changing market structures are the main

\footnotetext{
22 For this purpose, we made use of Mathematica, version 4, from Wolfram Research Inc.

23 Note that we calibrated the upper boundary of the distribution as to let almost all firms adopt the Internet. (The final number of adopters is 999 out of 1000.)
} 
determinants. The dynamics of this system imply that in the initial phase of the diffusion process, the mark-up on marginal production cost will increase. This is caused by monopolistic behaviour of the few Internet users. As more firms invest in the Internet, competitive pressure starts to increase both among the users of the Internet and among the non-users and the mark-up starts to decrease. This evolution of the mark-up is exactly the same as is found by Brayton et al. (1999) in their search for an explanation of low inflation in the information-based economy. This implies that the prices on the output market decrease, conditional on constant factor prices, e.g. on constant wages and constant energy prices. If the diffusion process stops, even in the case where some firms do not invest in the Internet, the markets return to a situation with a constant mark-up on unit production cost and constant prices.

Concerning inflation, the process described above implies that, if we assume constant wages and other factor prices, inflation decreases during the diffusion process. In the case of increased wages, which is the case in the current low-inflation/high growth experience in the US, the increase in production cost is compensated by the decrease of the mark-up such that we indeed can explain the current low inflation experience. However, in the end when the diffusion process stops, the mark-up will return to its old value and inflation will start rising if the upward pressure from the labour market persists. So this model can explain low inflation, combined with high output growth and low unemployment, but only for the short term. The model predicts that in the long run inflation will return to its 'normal' value. ${ }^{24}$ Note that the productivity explanation found in the literature - where changes in the growth rate of productivity are not incorporated instantaneously in the wage rate - works in the same direction and is also temporary in nature. So both effects amplify each other but also have a temporary effect on inflation.

The model presented here has some shortcomings, mainly because we wanted to present a model that is as simple as possible and that focuses on the main issues to be addressed. One of the points to be improved is the currently missing supply side of intermediary goods and the use of the Internet by these firms. In a more elaborate version, both the supply and the demand side of the intermediary goods market could be modelled explicitly. This also gives a more complete view on the entire value chain of products and services. Also including the final product market would make the whole picture complete.

Finally, the treatment of expectations is rather poor in the current version of the model. Firms assume that profits and investment costs remain constant, and thus expect that the number of users of the Internet does not change. This is not very realistic. However, another extreme view is that firms know the behaviour of all other firms, including their (expected) adjustment costs, and that each firm knows the exact date of adoption of all other firms. This would be not very realistic too. A position somewhere in between by assuming some sort of restricted information or adaptive expectations would cancel out the drawbacks of the two extremes. However, in all

\footnotetext{
${ }^{24}$ Structural effects of Information and Communication Technologies on inflation are for instance increased labour market efficiency as described by e.g. Ziesemer (2003) and Ihrig and Marquez (2004).
} 
these cases the extensions and improvements would bear the risk that the main point to be addressed in the paper - the explanation of low inflation by using an endogenous diffusion model of Internet investments - would move to the background.

Finally, this paper shows the importance of network effects and argues that the existence of open standards leads to a vast amount of competitive but compatible products. Though the products themselves can be appropriated, the standards on which they are based are not. A non-open standard would cause monopoly power and this would hamper the spread of compatible applications that are needed to implement the Internet strategies successfully and at (relative) low costs. Policies to foster open standards are desirable to encourage the development of future applications that integrate EDI and the Internet to a larger extent.

\section{Acknowledgement}

I would like to thank the editor of this journal and an anonymous referee for their comments on an earlier version of this paper. Any remaining errors are my own.

\section{Appendix A. Determination of the parameters}

The total number of firms in the sub-market is set to $n=1000$. The original marginal costs are equal to $c_{0}=10$ whereas the initial marginal costs if one firm uses the Internet is set to $c_{1,0}=9.9$. The parameter $\beta$ is set to 1.1 such that the ultimate marginal cost decrease to $9.9 / 1.1=9$. This implies that using the Internet reduces the marginal cost by $10 \%$. The number of users in Eq. (7) is multiplied by a factor $\delta=0.1$ as to calibrate the speed of diffusion. The constant of the linear demand function $a$ is set to 1000 . For these parameters, we calculate the profits for the users for all possible number of users, i.e. for $m=1 . . n$. From that we can determine the minimum and maximum profits $\left(\pi_{\min }\right.$ and $\left.\pi_{\max }\right)$. For the upper boundary of the distribution, we arbitrarily set a factor $\gamma_{\max }>1$ such that the expected total investment costs, including adjustment cost and discount factor, of the firm with the highest value of these costs is equal to $I_{\max }^{\mathrm{UCC}}=\gamma_{\max } \cdot \pi_{\max }$. Choosing $\gamma_{\max }$ larger than one implies that there are some firms who will never invest in the Internet. For the lower boundary of the distribution, we calibrated the lower bound of the uniform distribution by choosing a fraction $0<\gamma_{\min }<1$ such that $\operatorname{CDF}\left(\pi_{1}(0)-\pi_{0}(0), \gamma_{\min } \cdot \pi_{\min }, \gamma_{\max }\right.$. $\left.\pi_{\text {max }}\right) \cdot n>1$, where $\operatorname{CDF}(a, b, c)$ is defined as the cumulative distribution function (of the uniform distribution) evaluated at value $a$, for lower and upper boundaries $b$ and $c$, respectively. This means that as soon as the Internet technology becomes available, there is at least one firm for which it is profitable to invest in it, even if there are no network effects. That is why we have chosen $c_{1,0}<c_{0}$. Moreover, we have chosen a sufficient large value of $\alpha$ such that $\operatorname{CDF}\left(\pi_{1}(1)-\pi_{0}(1), \gamma_{\min } \cdot \pi_{\min }\right.$, $\left.\gamma_{\max } \cdot \pi_{\max }\right) \cdot n>2$, which says that the network effects are sufficient strong as to attract at least one other firm to become an Internet user. For the simulation these parameters are: $\alpha=0.995, \gamma_{\min }=0.9965$ and $\gamma_{\min }=1.2$. The user cost of capital of 
Internet investments is implicitly given by these parameters. Finally, for the non-linear demand function $\varepsilon$ is set to 2 .

\section{References}

Akerlof, G.A., Dickens, W.T., Perry, G.L., 1996. The macroeconomics of low inflation. Brookings Papers on Economic Activity.

Ball, L., Mankiw, N.G., 2002. The NAIRU in theory and practice. Journal of Economic Perspectives. 16 , 115-136.

Ball, L., Moffitt, R., 2001a. Productivity Growth and the Phillips Curve. The Roaring Nineties: Can Full Employment Be Sustained. Foundation Century Foundation Press, New York, Russell Sage, pp. 6190.

Ball, L., Moffitt, R., 2001b. Productivity growth and the Phillips curve. National Bureau of Economic Research, Inc., NBER Working Papers, 8421.

Becchetti, L., Londono, D.A., Bedoya, Paganetto, L., 2003. ICT investment, productivity and efficiency: evidence at firm level using a stochastic frontier approach. Journal of Productivity Analysis 20 (2), 143-167.

Berndt, E.R., Malone, T.W., 1995. Information technology and the productivity paradox: Getting the questions right. Economics of Innovation and New Technology 3, 177-182.

Bertschek, I., 2003. Information technology and productivity gains and cost savings in companies. In: Jones, D.C. (Ed.), New Economy Handbook. Academic Press, California, London, pp. 214-228.

Blanchard, O., Katz, L.F., 1997. What we know and do not know about the natural rate of unemployment. Journal of Economic Perspectives 11, 51-72.

Blanchflower, D.G., Oswald, A.J., 1995. An introduction to the wage curve. Journal of Economic Perspectives 9, 153-167.

Brayton, F., Roberts, J.M., Williams, J.C., 1999. What's happened to the Phillips curve?. Board of Governors of the Federal Reserve System (US), Finance and Economics Discussion Series: 199949.

Daveri, F., 2002. The new economy in Europe, 1992-2001. Oxford Review of Economic Policy 18 (3), 345 362.

Diewert, W.E., Fox, K.J., 1999. Can measurement error explain the productivity paradox. Canadian Journal of Economics 32, 251-280.

EITO, 2000. European Information Technology Observatory, Millenium ed. (EITO).

Gordon, R.J., 2000. Does the new economy measure up to the great inventions of the past?. Journal of Economic Perspectives 14, 49-74.

Hall, B.H., Khan, B., 2003. Adoption of new technology. In: Jones, D.C. (Ed.), New Economy Handbook. Academic Press, California, London, pp. 229-249.

Ihrig, J., Marquez, J., 2004. An empirical analysis of inflation in OECD countries. International Finance 7 (1), 61-84.

Jalava, J., Pohjola, M., 2002. Economic growth in the new economy, evidence from advanced economies. Information Economics and Policy 14, 189-210.

Jorgenson, D.W., 2001. Information technology and the US economy. American Economic Review 91 (1), $1-32$.

Katz, M.L., Shapiro, C., 1986. Technology adoption in the presence of network externalities. Journal of Political Economy 94, 822-841.

Kiley, M.T., 2003. Why is inflation low when productivity growth is high?. Economic Inquiry 41, $392-406$.

Maskin, E., Tirole, J., 1987. A theory of dynamic oligopoly, III: cournot competition. European Economic Review 31, 947-968.

Meijers, H., 2004. Productivity in Europe and the US: ICTs and the role of network effects. Communications and Strategies 0 (54), 161-188.

Moulton, B.R., 2000. GDP and the digital economy: keeping up with the changes. In: Understanding the Digital Economy: Data, Tools, and Research. MIT Press, Cambridge and London, pp. 34-48. 
Pilat, D., Lee, F., van Ark, B., 2002. Production and use of ICT: a sectoral perspective on productivity growth in the OECD area. OECD Economic Studies 0 (35), 47-78.

Reinganum, J.F. 1989. The timing of innovation: research, development and diffusion. In: Schmalensee, R., Willig, R.D. (Eds.), Handbook of Industrial Organization, North-Holland, Amsterdam, I, pp. 850 908.

Staiger, D., Stock, J.H., Watson, M.W., 2001. Prices, wages, and the US NAIRU in the 1990s. The roaring nineties: Can full employment be sustained? New York, Russell Sage Foundation Century Foundation Press, pp. 3-60.

Stein, T., Sweat, J., 1998. Killer supply chains, six companies are using supply chains to transform the way they do business. Information Week.

Stiroh, K.J., 2002. Are ICT spillovers driving the new economy?. Review of Income and Wealth 48 (1), 33 57.

Stoneman, P., 2002. The Economics of Technological Diffusion. Blackwell Publishers Ltd, Oxford.

Thirtle, C.G., Ruttan, V.W., 1987. The Role of Demand and Supply in the Generation and Diffusion of Technical Change. Harwood Academic Publishers, Chur.

Triplett, J.E., 1999. Economic statistics, the new economy, and the productivity slowdown. Business Economics 34, 13-17.

US Department of Commerce, 1998. The Emerging Digital Economy.

van Ark, B., 2002. Measuring the new economy: an international comparative perspective. Review of Income and Wealth 48 (1), 1-14.

van Ark, B., Inklaar, R., McGuckin, R.H., 2003. The contribution of ICT-producing and ICT-using industries to productivity growth: a comparison of Canada, Europe and the United States. International Productivity Monitor 0 (6), 56-63.

Yi, S.-S., 1999. Market structure and incentives to innovate: the case of cournot oligopoly. Economics Letters 65 (3), 379-388.

Ziesemer, T., 2003. Information and communication technology as technical change in matching and production. Journal of Economics (Zeitschrift fur Nationalokonomie) 79 (3), 263-287. 